\title{
PENGARUH BRAND IMAGE, SERVICE QUALITY DAN PRICE TERHADAP REPURCHASE INTENTION PADA GREENLIGHT BANDUNG
}

\author{
Adil Musty Tamzil, Kuswanti, Mediana Urfah
}

Universitas Kristen Marnatha Bandung Jawa Barat, Indonesia

Email: adil.tamzil@gmail.com, ckwanty@gmail.com, meydianaurfah15@gmail.com

\begin{abstract}
Abstrak
Keputusan minat beli berulang konsumen merupakan suatu Tindakan mengkonsumsi produk yang sama lebih dari satu kali ditentukan konsumen. Hal ini berdasarkan pada komitmen psikologis konsumen terhadap produk atau jasa yang disebabkan oleh pengalamannya setelah menggunakan produk tersebut, sehingga timbul keinginan untuk konsumsi ulang. Gagasan atau minat melakukan pembelian ulang muncul karena dipengaruhi oleh beberapa faktor tertentu, diantaranya yaitu "citra merek (brand image), kualitas pelayanan (Service Quality) dan Harga (Price)". Tujuan dari penelitian adalah guna mengukur pengaruh Citra merek, kualitas pelayanan dan harga pada keinginan membeli ulang pada Greenlight Bandung. Metode penelitian yang dipergunakan merupakan metode deskriptif verifikatif. Sampel yang digunakan terdapat 115 responden. "Pengolahan data mempergunakan analisis regresi linear berganda, koefisien determinasi, koefisien korelasi dan pengujian hipotesis."Dari hasil analisis (uji t) didaptkan Brand Image, Service quality, dan Price baik secara parsial memiliki pengaruh sigifikan pada Repurchase intention. Berdasarkan hasil uji hipotesis (uji F) dan koefisien determinasi mempertunjukkan secara stimultan diperoleh pengaruh signifikan pada Brand image (X1), Service Quality (X2) dan Price (X3) terhadap Repurchase intention.
\end{abstract}

Kata Kunci: citra merek; kualitas layanan; harga; niat pembelian kembali

\section{Abstract}

The decision of interest repeatedly consumerswill be a step a thing again from one time consumers. This swings to the commitment of consumer commitment to products or services that berbian so the way after the product, so that it arises want to be repeated. Questions or interests in repurchase have arisen in the past by certain factors, namely "brand image, quality of service (Service Quality) and Price (Price)". The purpose of his research is to use the influence of brand image, service and price eventually finally at Greenlight Bandung. The research force is described as descriptively verificative. Which sample used 115 victims. "Water data enhances multiple linear regression analysis, determination coefficient, correlation coefficient and test hypothesis." From the results of the analysis (test $t$ ) tapped Brand Image, Quality of service, and Good price both good good both partial influence sigifikan on repurchase intention. The hypothetical test results (test $F$ ) and the coefficient of determination make the sound stimult of the influence on the Brand image (X1), Service Quality (X2) and Price (X3) on repurchase intentions.

$\begin{array}{ll}\text { How to cite: } & \text { Tamzil, Adil Musty, Kuswanti, Mediana Urfah (2021) Pengaruh Brand Image, Service Quality dan } \\ & \begin{array}{l}\text { Price Terhadap Repurchase Intention pada Greenlight Bandung, Syntax Idea, 3(7). https:// } \\ \text { doi.org/10.36418/syntax-idea.v3i7.1355 }\end{array} \\ \text { E-ISSN: } & \text { 2684-883X } \\ \text { Published by: } & \text { Ridwan Institute }\end{array}$


Keywords: brand image; service quality; price; repurchase intention

\section{Pendahuluan}

Pemerintah mendukung kreativitas masyarakat yang diwujudkan dibidang usaha ekonomi industri kreatif, dukungan yang di berikan dengan melalui kebijakan yang menstimulus perkembangan industi kreatif. Dukungan ini merupakan peluang untuk para pelaku bisnis berinvestasi, baik..skala kecil, menengah maupun besar (Purnomo, 2016).

Ketertarikan pebisnis yang telah berinvestasi pada jenis usaha ini, tentunya perlu dipertimbangkan dengan bermacam-macam strategi marketing yang komprehensif, dengan cara memprediksi peluang yang ada di pasar, salah satunya melalui produk yang akan ditawarkan. Usaha clothing, adalah contoh jenis usaha yang bergerak pada industri kreatif. Di kota-kota besar di Indonesia industri seperti ini tumbuh subur dikarenakan peluang pasanya terbuka akibat kebutuhan masyarakat akan pakaian selalu ada (Hanggraeni, 2021).

Salah satunya di kota Bandung. Telah tumbuh dan berkembang distro-distro, yang berperan mendorong peningkatan kunjungan wisata, dan mengambil bagian dalam pertumbuhan industri kreatif ini.

Akibat pertumbuhan tersebut, membuat para pengusaha industri kreatif memerlukan teknik pemasaran efektif, guna bersaing pada persaingan yang semakin ketat. Menciptakan dan menumbuhkan citra merek (Brand Image) yang positif di benak masyarakat menjadi salah satu strategi pemasaran dalam mengatasi persaingan.

Salah satu sasaran strategi perusahaan adalah menempatkan mereknya di tempat tertinggi pada benak konsumennya. Untuk menciptakan brand yang baik perusahaan dituntut agar dapat menonjolkan manfaat dan kekhasan yang ditawarkan oleh merek atau produk itu sendiri, serta yang mampu memenuhi harapan konsumen. Cara ini akan dapat merubah pandangan konsumen tentang produk yang ditawarkan terlihat lebih baik didibanding para saingannya.

Kualitas layanan yang bermutu dibutuhkan guna memberikan daya tarik pada konsumen. Kualitas pelayanan akan memenuhi harapan konsumen, dan akan besar pengaruhnya terhadap minat pembelian konsumen. Kualitas layanan yang diasumsikan Konsumen akan dibandingkan dengan kualitas layanan perusahaan pesaing, dan penambahan nilai diperlukan melalui pelayananya, sehingga menjadi sebuah kelebihan ketimbang pesaing. Dengan demikian hal ini guna menambahkan daya saing (Windarti \& Ibrahim, 2017).

Di samping faktor brand image dan kualitas..pelayanan, terdapat faktor lain, yakni harga. Faktor ini juga menjadi salah satu yang sering dipertimbangkan oleh pelanggan sebelum membeli. Jika harga lebih rendah ketimbang pesaing maka permintaan produk meningkat, dan begitu juga sebaliknya. Perhatian dari konsumen akan didapatkan apabila terdapat ketepatan penyesuaian harga yang mengakibatkan pembelian produk.

"Harga adalah salah satu kunci yang cukup memiliki pengaruh yang kuat dan nyata pada sebuah putusan dari pembelian. Konsumen memiliki kecenderungan melihat, harga sebagai sebuah indikator nilai yang mana harga sesuai dengan 
kegunaan yang dikonsumsi sebuah jasa atau barang” (Fandy Tjiptono, 2016). “ Pembeli yang memiliki potensi berkecenderungan membutuhkan bermacam info atau masukan yang lebih cenderung lebih khusus, yang bisa didapatkan melalui harga penjualan sebelum membeli " (Sutisna, 2013).

Penelitian terdahulu juga mengungkapkan bahwa kepuasan merek merupakan konsekuensi brand experience (Sahin, Zehir, \& Kitapçı, 2011) dan brand image (Dunuwille \& Pathmini, 2016).

Pemahaman tentang penetapan sebuah harga sangat mempengaruhi minat pembelian ulang para konsumen. Strategi dengan dasar efektifitas haruslah diaplikasikan perusahaan.

\section{Brand Image (Citra Merek)}

Menurut (Philip Kotler, Keller, Ancarani, \& Costabile, 2014) "Kesan di kepala konsumen didasari pengalaman dan pesan-pesan merupakan citra merek". Brandd image terdiri dari pengetahuan dan keyakinan konsumen tentang merek beragam produk dan atribut non-produknya (Lee, H., Lee, C. and Wu, C. (2011). Semakin luas persepsi citra positif, negative, kognitif dan afektif dari suatu merek dapat dicapai melalui teknik pilihan bebas (Suman \& Garg, 2012).

\section{Dimensi Brand Image}

Menurut (Aaker, David A, 2014) "menjabarkan pada ketiga dimensi citra merek yang didalamnya terdiri atas citra dari perusahaanya, citra dari pemakainya dan citra dari produknya."

1. "Citra Perusahaan

Merupakan kolektif assosiasi pemahaman konsumen pada suatu perusahan yang memproduksi jasa atau produk."

2. "Citra Pemakai

Adalah kolektif pemahaman konsumen pada pengguna jasa atau produk tertentu."

3. "Citra Produk

Merupakan pemikiran kolektif yang dipersepsikan konsumen pada jasa atau produk tertentu."

\section{Kualitas Pelayanan (Service Quality)}

Lewis dan Booms dikutip (Fandy Tjiptono, 2016) mengemukakan:

"Kualitas dari pelayanan merupakan sebuah tolak ukur tingkat kualitas sebuah pelayanan perusahaan demi kepuasan konsumen. Wujud kualitas dari suatu layanan merupakan pemenuhan. keinginan dan ketepatan guna, yang dapat mengimbangi harapan pelangganya". Definisi kualitas layanan menyatakan bahwa ini adalah hasil dari perbandingan yang dibuat pelanggan antara layanan mereka harapan tentang layanan dan persepsi mereka tentang cara layanan telah dilakukan (Akbar \& Parvez, 2009). Menurut (Suman \& Garg, 2012), pelanggan akan menilai kualitas pelayanan rendah jika kinerja tidak memenuhi harapan dan kualitas tinggi ketika kinerja melebihi harapan. 


\section{Dimensi Kualitas Pelayanan}

Parasuraman. et.al dikutip (Lupiyoadi \& Hamdani, 2006) mengemukakan bahwa "lima dimensi kualitas jasa yaitu Berwujud, Empati, Keandalan, Ketanggapan, dan Jaminan."

1. "Berwujud (Tangible)

Kebisaan badan usaha untuk menyatakan keberadaannya pada pihakpihak di luar perusahaan."

2. "Empati (Emphaty)

Memberikan perhatian pada perorangan yang tulus melalui pemahaman tentang kebutuhan para pelangan."

3. "Keandalan (Reliability)

Keahlian badan usaha melayani pelanggan yang memiliki kesamaan dengan yang dijanjikan."

4. "Ketanggapan (Responsiveness)

Suatu kebijakan yang tepat dan cepat dalam memberikan sebuah pelayanan pada pelanggan."

5. "Jaminan (Assurance)

Kesopan-santunan, pengetahuan dan juga keahlian para pekerja badan usaha yang akan menimbulkan rasa percaya pelanggan terhadap perusahaan”. (Etemad-Sajadi \& Rizzuto, 2013) juga mengemukakan bahwa lima dimensi SERVQUAL yang digunakan dalam industri makanan siap saji.

\section{Harga (Price)}

Berdasarkan (Philip Kotler et al., 2014) "Bagian dari elemen bauran pemasaran membuat sebuah penghasilan untuk perusahaan, elemen bauran yang lain menghasilkan biaya merupakan harga. Harga mudah dapat disesuaikan, sedangkan elemen lainnya membutuhkan banyak usaha dan waktu".

\section{Dimensi Harga}

Menurut (Philip dan Gary Amstrong Kotler, 2016) “mengemukakan terdapat empat dimensi harga, yaitu:

1. Terjangkaunya harga.

2. kesinambungan harga terhadap kualitas.

3. Kemampuan bersaing dari harga.

4. Sesuainya harga terhadap manfaat."

\section{Minat Beli Ulang (Repurchase Intention)}

Menurut (Jerry C. Olson dan Peter J. Paul, 2014) mengemukakan: “Aktifitas pembelanjaan berulang, yang merupakah hasil dari kepuasan konsumen dengan kata lain konsumen merupakan konsumen loyal. Perilaku ini juga bisa mendorong konsumen bercerita pengalaman baik atau kepuasannya pada yang lain". Repurchase intention is a manifestation of customer loyalty (Vickers, 2017).

\section{Dimensi Minat Beli Ulang}

Ferdinand yang dikutip Basrah dan Samsul tahun 2014 "minat beli terdapat empat dimensi yakni:

1. Minat transaksional-Konsumen memiliki kemungkinan besar melakukan pembelian berulang. 
2. Minat referensial - Konsumen mau meberikan rekomendasi pada yang lain.

3. Minat preferensial - Suatu produk dijadikan pilihan yang utama oleh konsumen.

4. Minat eksploratif - Konsumen memiliki daya Tarik mencari info tentang produk yang disukai."

5 .

\section{Metode Penelitian}

Menurut (Sugiyono, 2016) berpendapat "Cara ilmiah memperoleh data yang akan digunakan untuk suatu tujuan merupakan metode penelitian."

\section{Populasi dan Teknik Sampling}

Menurut (Sugiyono, 2016) menyatakan populasi merupakan: “subjek atau objek memiliki karakteristik tertentu dan kualitas yang telah diputuskan sebelumnya dengan tujuan agar dapat dipelajari dan kemudian disimpulkan."

Menurut (Sugiyono, 2016) berpendapat "Sebagian kecil atau karakter yang dipunyai populasi disebut sampel".

\section{Uji Validitas}

Menurut (Bilson Simamora, 2012) menyatakan”sebuah pengukuran yang menggambarkan tikatan kesahaan atau kevalidan sebuah instrumen disebut validitas."

Kriteria pengujian validitas menurut (Bilson Simamora, 2012)

- "Apabila $r$ hitung $>\mathrm{r}$ tabel, valid dinyatakan pada butir pernyataan."

- "Apabila rhitung< $\mathrm{r}$ tabel, butir dari penrnyataan dinyatakan tidak valid."

\section{Uji Reliabilitas}

Menurut (Sugiyono, 2016) menguraikan bahwa "pengertian realibilitas adalah dapat dipercayanya sebuah hasil dari pengukuran, tingkat reliabilitas dinyatakan baik apabila hasil pengukuran yang diperoleh cenderung sama."

Menurut (Umar, 2004), "untuk penetapan butir-butir instrumen yang baik yaitu koefisien Cronbach Alpha $\alpha>0,60$ maka memiliki tingkat reliabilitas yang bagus.

\section{Analisis Regresi Linier Berganda}

"Analisis regresi linear berganda merupakan persamaan model dengan kemampuan menjelaskan sebuah hubungan antar variable bebas dan terikat." Rumus yang dipergunakan:

$$
\mathrm{Y}=\alpha+\mathrm{b} 1 \mathrm{X} 1+\mathrm{b} 2 \mathrm{X} 2+\mathrm{b} 3 \mathrm{X} 3+\square
$$

\section{Analisis Koefisien Kolerasi}

"Analasis kolerasi adalah suatu analisis agar memperoleh kekuatan atau derajat hubungan variabel bebas, terikat."

Rumus kolerasi adalah:

Dimana:

$\mathrm{r}_{\chi \gamma}=$ koefisien kolerasi pearson

$\mathrm{n} \quad=$ jumlah responden dalam uji instument

$\mathrm{X}=$ variabel bebas

$\mathrm{Y}=$ variabel terikat 


\section{Koefisien Determinasi (R2)}

"Koefisien determinasi dipergunakan pengukuran kemampuan penjabaran variasi variable independent pada model."

Dengan rumus berikut:

$\mathrm{Kd}=\mathrm{r}^{2} \times 100 \%$

Dengan jabaran:

$\mathrm{Kd}=$ koefisien determinasi

$\mathrm{r} \quad=$ koefisien korelasi

\section{Uji Hipotesis Parsial (Uji t)}

"pengujian $t$ akan menunjukan pengaruh dari variable independent dengan sifat parsial yang dapat menggambarkan variable dependen."

Menghitung Uji t (t-test)

$$
t=\frac{b_{i}}{S b_{i}}
$$

\section{Uji Hipotesis Simultan (Uji f)}

"Uji f menggambarkan pengaruh dengan cara bersamaan pada variable bebas terhadap variable terikat."

Menghitung Uji (F-Test)

$\mathrm{R}^{2} / \mathrm{k}$

$$
\mathrm{F}=\frac{}{\left(1-\mathrm{R}^{2}\right) /(\mathrm{n}-\mathrm{k}-1)}
$$

\section{Hasil dan Pembahasan}

\section{Uji validitas}

Seluruh pernyataan dalam questioner dinyatakan valid karena seluruh rhitung dalam pernyataan di setiap bulir pada questioner lebih besar daripada rtabel yakni 0,176 .

\section{Uji Realibilitas}

a. Untuk variable Brand image didapatkan Cronbach's Alpha sebesar 0.954, oleh karena itu kuesioner variabel ini reliabel karena >0.60. Maka dapat dikatakan reliabel oleh karena itu dapat dipergunakan sebagai instrument pengukuran.

b. Untuk variable Service Quality Untuk variabel Brand Image $\left(\mathrm{X}_{2}\right)$ didapatkan Cronbach's Alpha 0.948, oleh karena itu kuesioner variabel ini dikatakan reliabel karena >0.60. Maka dapat dikatakan reliabel oleh karena itu dapat dipergunakan sebagai instrument pengukuran.

c. Untuk variabel price didapatkan Cronbach's Alpha 0.902, oleh karena itu kuesioner variabel ini dikatakan reliabel karena >0.60. Maka dapat dikatakan reliabel oleh karena itu dapat dipergunakan sebagai instrument pengukuran.

d. Sedangkan untuk variabel repurchase intention didapatkan Cronbach's Alpha 0.902 , oleh karena itu kuesioner variabel ini dikatakan reliabel karena $>0.60$. Maka dapat dikatakan reliabel oleh karena itu dapat dipergunakan sebagai instrument pengukuran. 


\section{Brand image, Service Quality, Price dan Repurchase intention pada Greenlight Bandung}

a. Pengaruh brand Image terhadap repurchase intention

Koefisien korelasi koefisien korelasi (R) sebesar 0,603. Hasil yang di peroleh berada diantara nilai 0,60 - 0,799 artinya brand image berpengaruh kepada repurchase intention.

koefisien determinasi didapatkan koefisien determinasinya sebesar 0,363 atau $36,30 \%$, artinya variable brand image mempunyai pengaruh terhadap repurchase intention sebesar $36,30 \%$ dan sisanya sebesar $63,70 \%$ dipengaruhi factor lain.

Berdasarkan uji hipotesis (uji t) dengan thitung sebesar 8,033 > ttable 1,980 menggambarkan bahwa brand Image memiliki pengaruh sigifikan pada repurchase intention. Hal tersebut menunjukan bahwa kesan pelanggan setelah mengunjungi dan membeli produk di Greenlight berpengaruh dalam tingkat pembelian kembali, artinya konsumen Greenlight yang sudah membeli produk merasa senang dan bangga akan produk yang dibelinya karena mempunyai kesan yang baik terhadap merek Greenlight sehingga konsumen tersebut berniat akan melakukan pembelian kembali serta dapat merekomendasikan kepada orang sekitarnya.

b. Pengaruh service quality terhadap repurchase intention

Koefisien korelasi koefisien korelasi (R) sebesar 0,706. Hasil yang di peroleh berada diantara nilai 0,60 - 0,799 artinya service quality berpengaruh kepada repurchase intention.

koefisien determinasi didapatkan koefisien determinasinya sebesar 0,578 atau $57,8 \%$, artinya variable service quality mempunyai pengaruh terhadap repurchase intention dengan besaran $57,80 \%$ dan $42,20 \%$ dipengaruhi faktor lain.

Berdasarkan uji hipotesis (uji t) dengan thitung sebesar $8.033>$ ttable 1.980 menggambarkan service quality mempunyai dampak signifikan pada repurchase intention. Dengan demikian kualitas pelayanan pada Greenlignt mempengaruhi konsumen untuk datang dan membeli kembali. konsumen yang datang selalu disambut ramah, cepat tanggap dan perhatian oleh karyawan Greenlight sehingga selain dapat produk yang bagus, konsumen juga merasa senang atas pelayanan yang diberikan oleh karyawan menjadikan Greenlight adalah clothing line yang akan didatangi kembali.

c. Pengaruh price terhadap repurchase intention

Koefisien korelasi koefisien korelasi (R) sebesar 0,756. Hasil yang di peroleh berada diantara nilai 0,60 - 0,799 artinya price berpengaruh kepada repurchase intention. koefisien determinasi didapatkan koefisien determinasinya sebesar 0,601 atau $70,1 \%$, artinya variable price mempunyai pengaruh terhadap repurchase intention dengan besaran $60,1 \%$ dan $39,9 \%$ dipengaruhi faktor lain. 
Berdasarkan uji hipotesis (uji t) dengan thitung sebesar $10.372>$ ttable 1.980 dan koefisien determinasi 0.701 menggambarkan variabel price memiliki pengaruh signifikan pada repurchase intention. Hal tersebut menunjukan bahwa tingi rendahnya harga yang dikeluarkan Greenlight berpengaruh terhadap repurchase intention. Greenlight mengeluarkan harga yang terjangkau baik untuk mahasiswa maupun yang sudah bekerja, sehingga konsumen puas karena mendapatkan produk bagus dengan harga yang wajar dan Greenlight juga mengeluarkan promo pada event atau tanggal-tanggal besar sehingga para konsumen yakin untuk datang dan membeli kembali.

d. Pengaruh brand image, service quality, dan price terhadap repurchase intention.

koefisien determinasi didapatkan koefisien determinasinya sebesar 0,701 atau $70,1 \%$, artinya variable brand image, service quality, price mempunyai pengaruh terhadap repurchase intention dengan besaran $70,1 \%$ dan $29,9 \%$ dipengaruhi faktor lain.

Berdasarkan uji mengetahui regeresi liniear berganda pengaruh brand image, service quality dan price terhadap minat beli diperoleh persamaan $\mathrm{Y}=$ $5,725+0,103 \mathrm{X}_{1}+0,204 \mathrm{X}_{2}+0,613 \mathrm{X}_{3}+\dot{\varepsilon}$ artinya konstata sebesar 5,725 menyatakan bahwa jika Brand image, service quality dan price $=0$ maka repurchase intention memiliki besaran 5,725. Dapat disimpulkan penambahan Brand image sebesar 1 dapat menaikan repurhchase intention sebesar 0,103. Penambahan Service quality sebesar 1 dapat menaikan repurchase intention sebesar 0,204, dan kenaikan price sebesar 1 dapat menaikan repurchase intention sebesar 0,613. hasil koefisien korelasi berganda (R) dengan besaran 0,815 , terdapat diantara nilai $0,80-1,000$ yang berarti brand image, service quality, dan price berpengaruh positif terhadap repurchase intention.

$F_{\text {hitung }}(111.004)>F_{\text {tabel }}$ (3,232), disimpulkan $\mathrm{H}_{0}$ ditolak dan $\mathrm{H}_{\mathrm{a}}$ diterimadengan artian brand image, service quality, dan price berpengaruh positif secara bersamaan terhadap repurchase intention.

\section{Kesimpulan}

Berdasarkan uji hipotesis (uji t) dengan thitung sebesar $12.446>$ table 1.980 dan koefisien determinasi 0.578 menggambarkan bahwa Brand Image memiliki pengaruh sigifikan pada Repurchase intention. Berdasarkan uji hipotesis (uji t) dengan thitung sebesar $8.033>$ ttable 1.980 dan koefisien determinasi 0.603 menggambarkan Service quality mempunyai dampak signifikan pada Repurchase intention. Berdasarkan uji hipotesis (uji t) dengan thitung sebesar $10.372>$ ttable 1.980 dan koefisien determinasi 0.701 menggambarkan variabel Price memiliki pengaruh signifikan pada Repurchase intention. Berdasarkan hasil uji hipotesis (uji F) dengan $F_{\text {hitung }}(111.004)>F_{\text {tabel }}$ $(3,232)$ dan koefisien determinasi 0.665 mempertunjukkan secara stimultan diperoleh pengaruh signifikan pada Brand image (X1), Service Quality (X2) dan Price (X3) terhadap Repurchase intention. 
Pengaruh Brand Image, Service Quality dan Price terhadap Repurchase Intention pada Greenlight Bandung

\section{BIBLIOGRAFI}

Aaker, David A, and Alexander L. Biel. (2014). Manajemen Ekuitas Merek: Memanfaatkan Nilai dari suatu Merek. Cetakan Ketiga. Jakarta: Penerbit Mitra Utama.

Akbar, Mohammad Muzahid, \& Parvez, Noorjahan. (2009). Impact of service quality, trust, and customer satisfaction on customers loyalty. ABAC Journal, 29(1). Google Scholar

Bilson Simamora. (2012). Riset Pemasaran, Jakarta: PT. Gramedia Pustaka Utama.

Dunuwille, V. M., \& Pathmini, M. G. S. (2016). Brand image and customer satisfaction in mobile phone market: study based on customers in Kandy district. Journal of Business Studies, 3(1), 1-13. Google Scholar

Etemad-Sajadi, Reza, \& Rizzuto, Daniela. (2013). The antecedents of consumer satisfaction and loyalty in fast food industry: A cross-national comparison between Chinese and Swiss consumers. International Journal of Quality \& Reliability Management. Google Scholar

Fandy Tjiptono. (2016). Pemasaran Jasa (Prinsip, Penerapan, Penelitian). Yogyakarta. Andi.

Hanggraeni, Dewi. (2021). Strategi Bisnis dan Manajemen Risiko dalam Pengembangan UMKM di Indonesia (Vol. 1). PT Penerbit IPB Press. Google Scholar

Jerry C. Olson dan Peter J. Paul. (2014). Perilaku konsumen dan strategi pemasaran. Edisi Sembilan. Buku 2.penerbit salemba empat.jakarta.

Kotler, Philip dan Gary Amstrong. (2016). Prinsip-Prinsip Pemasaran. Jakarta: Erlangga.

Kotler, Philip, Keller, Kevin L., Ancarani, Fabio, \& Costabile, Michele. (2014). Marketing management 14/e. Pearson.

Lupiyoadi, Rambat, \& Hamdani, A. (2006). Manajemen Pemasaran Jasa Edisi 2, penerbit Salemba Empat. Jakarta. Google Scholar

Purnomo, Rochmat Aldy. (2016). Ekonomi Kreatif Pilar Pembangunan Indonesia. Ziyad Visi Media.

Sahin, Azize, Zehir, Cemal, \& Kitapçı, Hakan. (2011). The effects of brand experiences, trust and satisfaction on building brand loyalty; an empirical research on global brands. Procedia-Social and Behavioral Sciences, 24, 12881301. Google Scholar

Sugiyono. (2016). Metode Penelitian Bisnis, Edisi kedelapan, Bandung; Penerbit 
Adil Musty Tamzil, Kuswanti dan Mediana Urfah

CV.Alfabeta.

Suman, M., \& Garg, R. (2012). Consumer Perception Towards Quality of Financial Services. Urban vs. Rural Perspective. Google Scholar

Sutisna. (2013). Perilaku Konsumen dan Komunikasi Pemasaran. PT. Remaja Rosdakarya, Bandung.

Umar, Hussein. (2004). Riset sumber daya manusia dalam organisasi. Gramedia Pustaka Utama. Google Scholar

Vickers, Neil J. (2017). Animal communication: when i'm calling you, will you answer too? Current Biology, 27(14), R713-R715. Google Scholar

Windarti, Tias, \& Ibrahim, Mariaty. (2017). Pengaruh kualitas produk dan kualitas pelayanan terhadap kepuasan konsumen produk donat madu (studi pada konsumen CV. Donat Madu Cihanjuang-Pekanbaru). Riau University. Google Scholar

\section{Copyright holder :}

Adil Musty Tamzil, Kuswanti, Mediana Urfah (2021)

First publication right :

Syntax Idea

This article is licensed under:

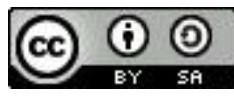

